\title{
ROCKBURST RISK ASSESSMENT BASED ON SOFT COMPUTING ALGORITHMS
}

\author{
Joaquim Tinoco $^{1}$, Luis Ribeiro e Sousa ${ }^{2}$, Tiago Miranda ${ }^{1}$, and Rita Leal e Sousa ${ }^{3}$ \\ ${ }^{1}$ Institute for Sustainability and Innovation in Structural Engineering, Department of Civil Engineering, \\ University of Minho, Guimarães, Portugal \\ ${ }^{2}$ Department of Civil Engineering, University of Porto, Portugal \\ ${ }^{3}$ Stevens Institute of Science and Technology, Hoboken, New Jersey, USA
}

Keywords: Rockburst, Risk Assessment, Soft Computing, Neural Networks

\begin{abstract}
A key aspect that affect many deep underground mines over the world is the rockburst phenomenon, which can have a strong impact in terms of costs and lives. Accordingly, it is important their understanding in order to support decision makers when such events occur.

One way to obtain a deeper and better understanding of the mechanisms of rockburst is through laboratory experiments. Hence, a database of rockburst laboratory tests was compiled, which was then used to develop predictive models for rockburst maximum stress and rockburst risk indexes through the application of soft computing techniques.

The next step is to explore data gathered from in situ cases of rockburst. This study focusses on the analysis of such in situ information in order to build influence diagrams, enumerate the factors that interact in the occurrence of rockburst, and understand the relationships between them. In addition, the in situ rockburst data were also analyzed using different soft computing algorithms, namely artificial neural networks (ANNs). The aim was to predict the type of rockburst, that is, the rockburst level, based on geologic and construction characteristics of the mine or tunnel.

One of the main observations taken from the study is that a considerable percentage of accidents occur as a result of excessive loads, generally at depths greater than $1000 \mathrm{~m}$. In addition, it was also observed that soft computing algorithms can give an important contribution on determination of rockburst level, based on geologic and construction-related parameters.
\end{abstract}




\section{INTRODUCTION}

Accidents and related problems can occur frequently in deep underground mines and other underground structures. Thus, it is essential to develop and implement risk analysis procedures to minimize their occurrence. Risk has a complex nature and results from the combination of two sets of factors: first, the events and their impacts; and second, the vulnerability factors that determine the probability of an event having a certain impact or consequence $[1,2]$.

Many researchers have collected, analyzed, and published reports on accident cases that have occurred in tunnels during construction and exploration [1,3]. Rockburst is one example of an accident that can occur during tunneling. It is a result of overstress of the rock mass or of the intact brittle rock, and happens when stresses exceed the compressive strength of the material. The impacts of rockburst range from spalling to sudden and violent failure of the rock mass. Depth is an important factor in the occurrence of this phenomena, since the stress exerted on the rock increases with depth.

In mining activities, other types of events have also been identified and classified, such as heat hazards and other events related to blasting cavities. Blasts, gas explosions, and fire are the most common hazardous events in China. In deep mining activities, major problems are also associated with large deformations and overstressing of the rock mass, which are caused by excavations at great depth, and which may result in rockburst. Comprehensive investigations of deep mining mechanics are thus of great interest [4].

Risk assessment can be managed with the aim of avoiding problems in underground construction. Risk management procedures can be significantly improved by using systematic techniques throughout the project's life. By using such techniques, potential problems can be clearly identified such that appropriate risk mitigation measures can be implemented in a timely manner. As a result, risk management became an integral part of most underground construction projects during the late 1990s [1,5].

During the construction of some of the underground structures of the Jinping II hydropower scheme in China, engineers were faced with the occurrence of several rockbursts [6]. As a result, a large study was conducted by the authorities to evaluate the accidents and to come up with mitigation measures and guidelines for construction under circumstances that are prone to rockburst. This study included the establishment of a database containing information regarding rockburst and a description of the events that had occurred, and led to the use of data mining (DM) techniques to determine the probability of occurrence of rockburst and its characteristics (i.e., type, location, depth and width, and time delay) [7].

We analyzed these events and concluded that the main mechanisms in rockburst are usually associated with local underground geometry, such as pillars and openings, and with the ground conditions [8]. Rockbursts are classified as strain bursts, pillar bursts, or fault slip bursts [9]. They usually occur during mining operations; however, they can also happen during the construction of civil underground structures, such as deep tunnels. In these cases, the most common phenomenon is strainbursting, although buckling and face crushing may also take place. In addition, impact-induced rockburst created by blasting, caving, and adjacent tunneling should be considered for less stressed and deformed rock formations.

The focus of this paper is on rockburst risk assessment, on the different types of rockburst events, and on their consequences to underground mining and construction. Two rockburst databases that were assembled by these authors are discussed. The first consists of a collection of rockburst laboratory experiments that were performed at the State Key Laboratory for 
GeoMechanics and Deep Underground Engineering (SKL-GDUE) in Beijing and that were the object of a publication in the journal of Engineering Geology for geological and geotechnical hazards [5]. The second consists of worldwide in situ cases of rockburst that occurred during mining and deep underground construction. The latter database was analyzed, and a list of factors that interact and influence the occurrence of rockburst was determined, along with the relationships between these factors. Finally, different DM techniques were applied to the rockburst databases with the aim of developing predictive models of rockburst index and type. The results are presented in detail in Sections 3, and the different techniques are compared.

\section{DATA MINING MODELING IN GEOENGINEERING}

The prediction of geotechnical formation behavior in geoengineering is complex, particularly during excavations in mining engineering. This complexity is related to uncertainties in the rock mass characterization. In important projects, a large amount of geotechnical data can assist in reducing uncertainties concerning the establishment of design values for the parameters [10]. In the case of rockburst occurrence, the problems are even more difficult to evaluate.

Such data can hold information on trends and patterns that can be used in decision-making and to optimize processes. Therefore, it is necessary to define standard ways of collecting, organizing, and representing data. DM techniques are automatic tools from artificial intelligence and pattern-recognition fields that enable the discovery of potential knowledge [11,12]. DM is an area of computer science that lies at the intersection of statistics, data management and databases, machine learning, artificial intelligence, pattern recognition, and other areas.

The formal and complete analysis process is called knowledge discovery from databases (KDD). KDD establishes the main procedures for transforming data into knowledge. The KDD process follows the steps indicated in Figure 1 [11]: collection of a target dataset, data warehousing, transformation of the data into adequate forms for the DM process, selection of a DM tool, relationship identification of DM (classes, clusters, associations), interpretation of results, and consolidation of discovered knowledge.

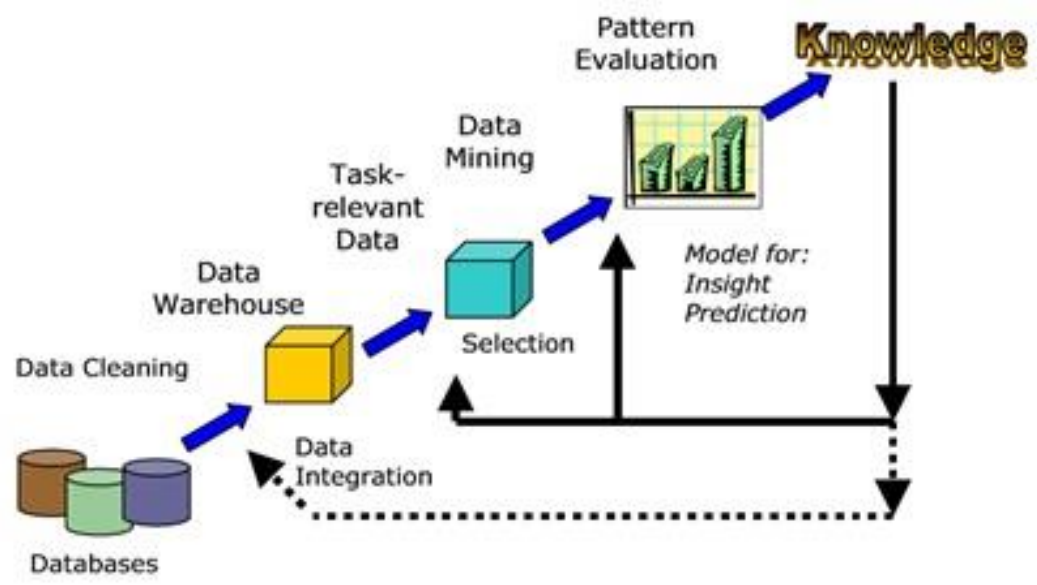

Figure 1: DM and the knowledge-discovery process [11].

Several DM techniques exist, each with its own purposes and capabilities. These include decision trees (DTs) and rule induction, neural networks, fuzzy modeling, support vector machines (SVMs), k-nearest neighbors (k-NN), instance-based algorithms, and learning classifier systems, among others [13,14].

Studies using a formal KDD framework are still uncommon in rock mechanics-related activities; however, when applied, they can provide important insight into the most influential parameters in the behavior of rock masses. An important example of such applications is a study 
done for the Deep Underground Science and Engineering Laboratory, which is located at the former Homestake gold mine in the United States [15]. Here, innovative regression models using different DM techniques were developed to analyze the strength and deformability of the host rock mass and to determine geomechanical indexes for the project [16]. One of the most important tasks in the KDD process is the DM step, which consists of choosing a learning algorithm for training and ultimately building a model that represents the data. Once the training phase is completed, the obtained model is evaluated using a test dataset that was not used during the learning process. The results consist of several different models; there is no universal model that can be used to efficiently solve all the problems.

A brief overview of the most relevant algorithms applied in previous studies is presented here. A DT is a tree-like graph that represents a set of rules for classifying data. These rules can be learned by using a class-labeled training dataset. Artificial neural networks (ANNs) are a deep-learning technique that is modeled after the way in which neurons operate within the human brain [16]. ANNs are formed by groups of artificial neurons connected in layers; signals travel from the first (input) layer to the last (output) layer, forming a structure that is similar to that of brain neurons. These networks, which can be learned from data, are particularly useful in complex applications to recognize patterns and predict future events. SVMs are supervised learning models that are normally used for data classification and regression analysis. Given categorized training data, SVMs determine an optimal plane that defines the decision boundaries, that is, the distance between classes [10].

Rockburst is affected by different factors. The influence diagram in Figure 2 [1] lists the factors that affect the probability of a rockburst and its potential consequences. Influence diagrams such as this are very important in the design of DM models for the analysis of accidental events such as rockburst.

Successful applications of DM to different types of problems already exist in the field of geoengineering [10]. Concerning rockburst phenomena, DM techniques were successfully applied to a rockburst laboratory test database obtained from tests at SKL-GDUE, China [5]. The developed triaxial rock test machine used to model the rockburst is presented in Figure 3 [5]. This equipment forms a true triaxial testing scheme; during the test, one surface of the specimen can be immediately unloaded from the true triaxial compression condition. In this way, it is possible to simulate the stress condition of the rock mass at the free excavation boundary in an underground excavation [5].

The database included a total of 139 cases with samples from different rock types located in China, Italy, Canada, and Iran. Two indexes were developed and used: $\sigma_{\mathrm{RB}}$, the rockburst maximum stress, and $I_{R B}$, the rockburst risk index. The meaning of these indexes is described in detail in the publication of He et al. [5]. DM techniques were applied to the rockburst database to infer prediction models of the indexes $\sigma_{\mathrm{RB}}$ and $\mathrm{I}_{\mathrm{RB}} . \sigma_{\mathrm{RB}}$ is the rupture stresses that are obtained in rockburst tests, while $I_{R B}$ is related to the rockburst critical depth [5]. New models were established using multiple regression (MR), ANNs, and SVM algorithms. 


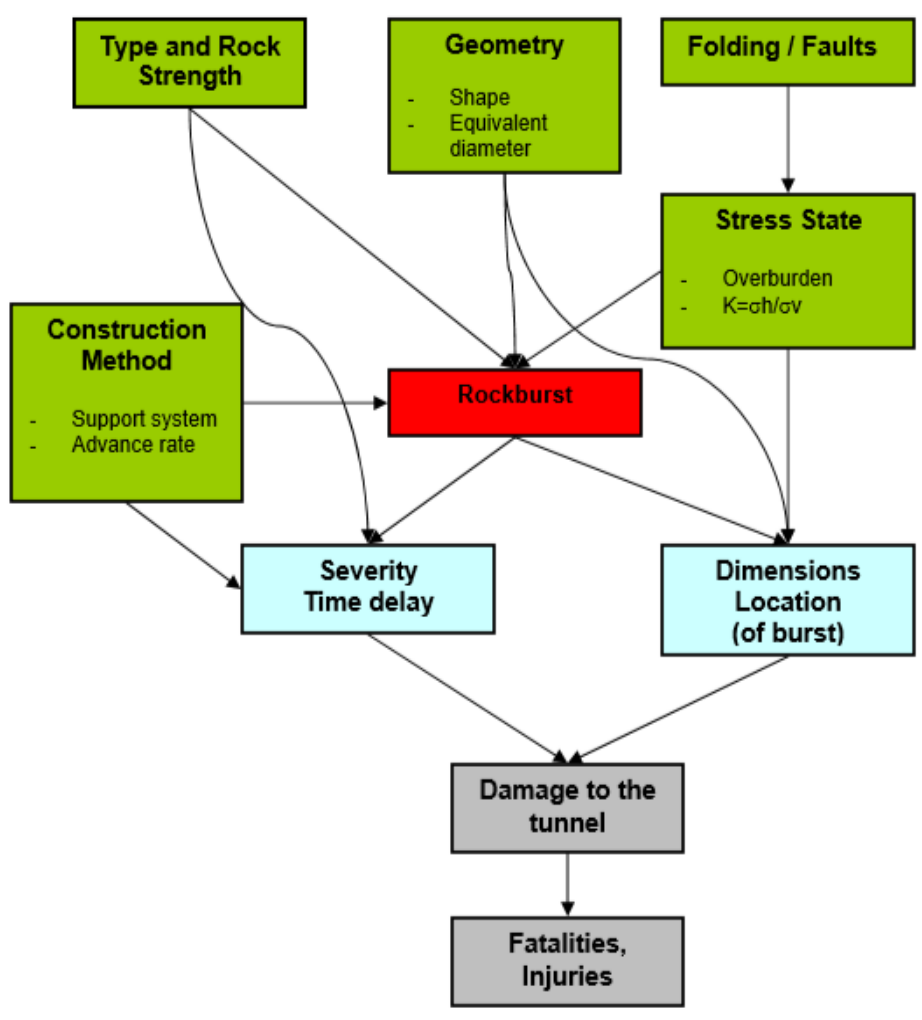

Figure 2: Influence diagram of rockburst [1].

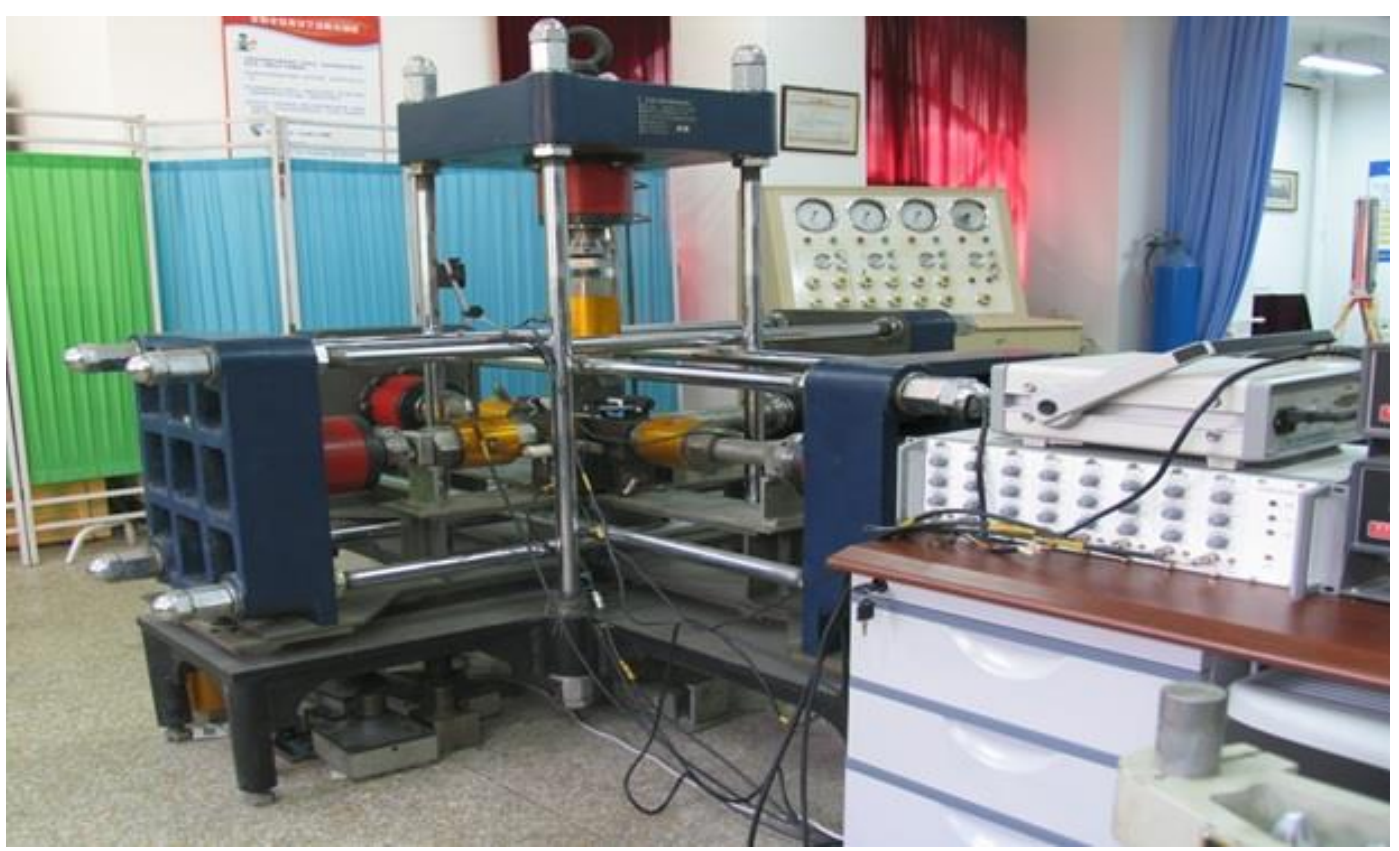

Figure 3: Rockburst laboratory testing system.

\section{DATA MINING APPLIED TO IN SITU ROCKBURST DATABASE}

In situ cases of rockburst that have occurred during tunnel construction/mining were collected via extensive research into publications and reports, and were organized into a database. The rockburst cases were classified according to their geometric characteristics, causes, and 
consequences. DM techniques were then applied to the database, with the aim of developing rockburst predictive models. In order to understand the circumstances in which rockbursts occur, their magnitude, and the different consequences of rockburst, we gathered as much information as possible on different aspects of the cases that could provide relevant information about the occurrence of the rockburst. For this purpose, a form was created that included eight fields, each with one or more variables. The eight fields included: a) rockburst occurrence, b) construction procedure, c) tunnel shape or geometry, d) rock strength, e) in situ existing stresses, f) location and dimensions of the rockburst, g) severity and time delay, and h) damage in the tunnel and associated equipment. The database contains 60 cases - a relatively small number. However, we believe that it constitutes an important first step in the development of more complex models in future. One important feature of the database is that most of the collected rockburst cases $(91 \%)$ occurred during the construction of hydroelectric underground power schemes. It is important to emphasize that a large number of the cases in which rockburst took place were located in deep underground mines. The collected data is confined to drill-and-blast and tunnel-boring machine excavation methods, and the shapes of the tunnels where the rockburst cases occurred were either circular $(67 \%)$ or horseshoe $(33 \%)$.

Different levels of rockburst were classified, as shown in Table 1, following the experience gained at the Jinping II hydropower scheme in China [6]. Figure 4 gives the distribution of cases in the database by rockburst type. In this figure, the Overbreak situation corresponds to levels C and D. Several DM techniques were applied to the database, including DT, k-NN, ANN, and SVM, with the aim of developing rockburst predictive models. The $\mathrm{R}$ environment [17] and the rminer package developed by Cortez [18] were used for the implementation of all DM techniques.

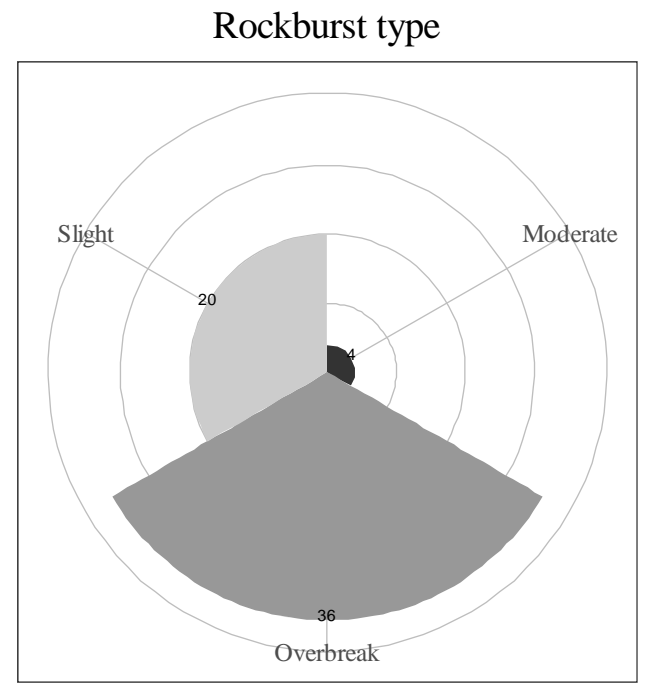

Figure 4: Distribution of cases by rockburst type.

Table 1: Margin settings.

\begin{tabular}{lllll}
\hline & Level A & Level B & Level C & Level D \\
\hline Description & Slight & Moderate & Strong & Very Strong \\
Duration & Sporadic exploration & Long duration & Fast & Sudden \\
Block depth & $<0.5$ & $0.5-1.0$ & $1.0-2.0$ & $>2.0$ \\
Impact in excavation & Small & Certain impact & Reasonable impact & Large impact \\
\hline
\end{tabular}


For the prediction of in situ rockburst type, a set of nine variables was considered:

- $\quad$ L - Length of occurrence $(\mathrm{m})$

- TESC - Type of excavation

- $\quad$ TSUP - Type of support

- UCS - Unconfined compressive strength (MPa)

- E - Young's modulus (GPa)

- $\mathrm{K}$ - horizontal vs. vertical stresses ratio K0

- FORM - Shape of the tunnel

- $\mathrm{D}_{\text {eq }}$ - Equivalent diameter (m)

- $\mathrm{R}_{\mathrm{eq}}-$ Equivalent radius (m)

The aim of this analysis was to develop models that would allow the prediction of the type of rockburst, given certain conditions and characteristics related to the underground work. For validation purposes, a leave-one-out method [18] was applied under 20 runs. The leave-oneout method consists of sequentially using one case to test the model, while the remaining cases are used to determine the model's structure. As a result, all data is used for training and testing. By using this method, $\mathrm{N}$ models are fitted, where $\mathrm{N}$ is the number of available data points. The final generalization estimate is evaluated by computing evaluation metrics for all $\mathrm{N}$ test samples.

For the evaluation and comparison of the models, we used three classification metrics based on a confusion matrix (Figure 5): recall, precision, and F1 score.

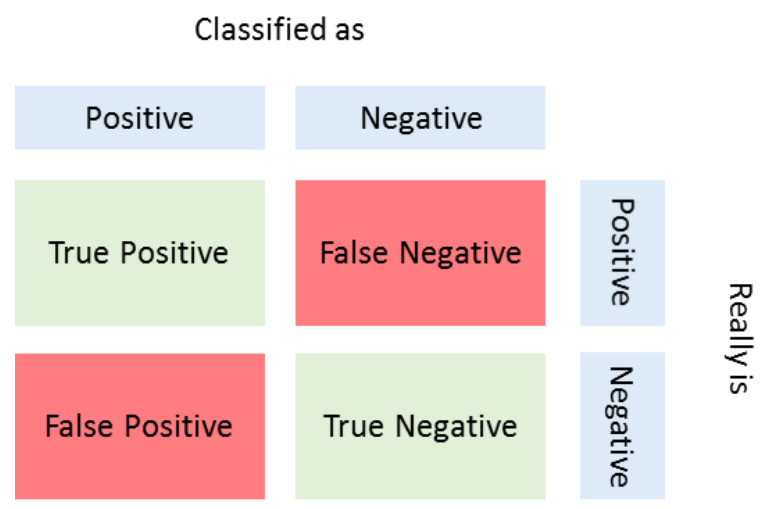

Figure 5: Establishment of a confusion matrix.

The recall measures the ratio of how many cases of a certain class were properly captured by the model. In other words, the recall of a certain class is given by

$$
\text { Recall }=\frac{\text { True positives }}{\text { True positives }+ \text { False negatives }}
$$

On the other hand, the precision measures the correctness of the model when it predicts a certain class. More specifically, the precision

$$
\text { Precision }=\frac{\text { True positives }}{\text { True positives }+ \text { False positives }}
$$


The $\mathrm{F}_{1 \text {-score }}$ represents a tradeoff between the recall and precision for a given class. It corresponds to the harmonic mean of precision and recall, according to the following expression:

$$
F_{1-\text { score }}=2 \cdot \frac{\text { Precision } \cdot \text { Recall }}{\text { Precision }+ \text { Recall }}
$$

For all three metrics, a higher value indicates better predictions. Figure 6 shows and compares the DM models' performance for in situ rockburst prediction based on recall, precision, and $\mathrm{F}_{1 \text {-score. }}$ Except for the Moderate rockburst level, all models presented a very good response, with F1 scores very close to $100 \%$. The low performance in predicting the Moderate class was expected, since only a few records were available for this class in the database for model training (around 7\%, as shown in Figure 4). However, we are confident that it will be possible to improve the model's response once more data for this class becomes available.

Another outcome of the application of the abovementioned DM techniques is the possibility of obtaining the importance of each of the model variables through sensitivity analysis [19]. Hence, and according to the ANN model, the relevant variables are K, TSUP, and L, which have a total influence of around $57 \%$ (Figure 7).

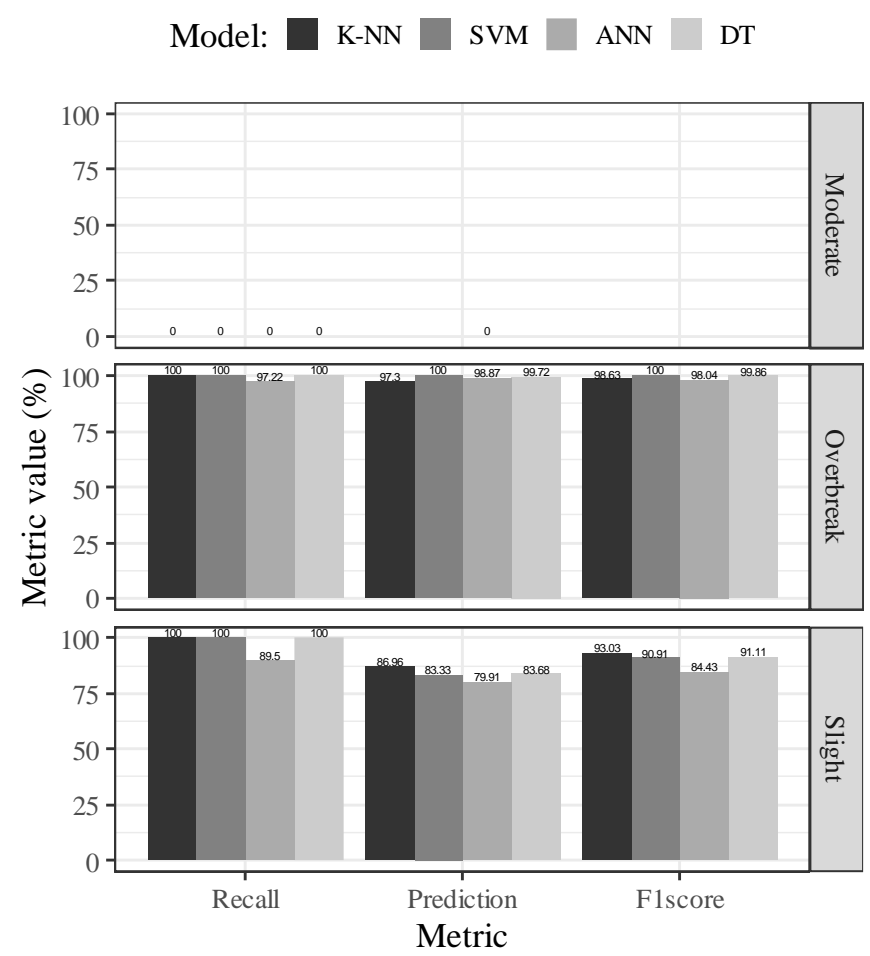

Figure 6: Comparison of DM models' performance for in situ rockburst prediction based on recall, precision, and $\mathrm{F}_{1 \text {-score }}$ metrics.

\section{FINAL REMARKS}

Several effective design methods are available to deal with ground fall in mining. However, this is not the case for rockbursts or for seismicity-related mine design problems. Modeling analyses have become a fundamental tool for assessing potential undesirable events, and their cost is only a small fraction of the potential benefits to excavation operations. A large variety of numerical analysis methods can and have been applied to underground engineering in order 
to assess the potential for the occurrence of rockburst. Monitoring of seismic events and visualization techniques in deep tunnels and mining activities are very useful tools for predicting potentially hazardous situations in order to assist the construction team in time.

Rockbursts are a type of event that can range from minor spalling to significant volumes of rock falling or being ejected with high energy, with devastating consequences. These phenomena are commonly reported in deep underground mining structures, but can also occur in deep tunnels such as the Jinping II hydropower scheme. This paper emphasized the importance of a rockburst triaxial experimental system for the prediction of these types of events, both in mining and in other deep underground projects. In addition, a previous analysis of rockburst test results allowed these authors to develop predictive models to estimate rockburst maximum stress and risk indexes.

A database of rockburst accidents that have occurred in mines and other underground works around the world, such as underground hydropower systems, was created for this study. Data analysis showed that a considerable percentage of accidents occur as a result of excessive loads, generally at depths greater than $1000 \mathrm{~m}$. The application of various DM techniques yielded different predictive models that focused on the determination of rockburst level, given geologic and construction-related parameters. All the developed models showed a high accuracy rate, allowing the importance of the several parameters involved in the prediction of rockburst level to be identified.

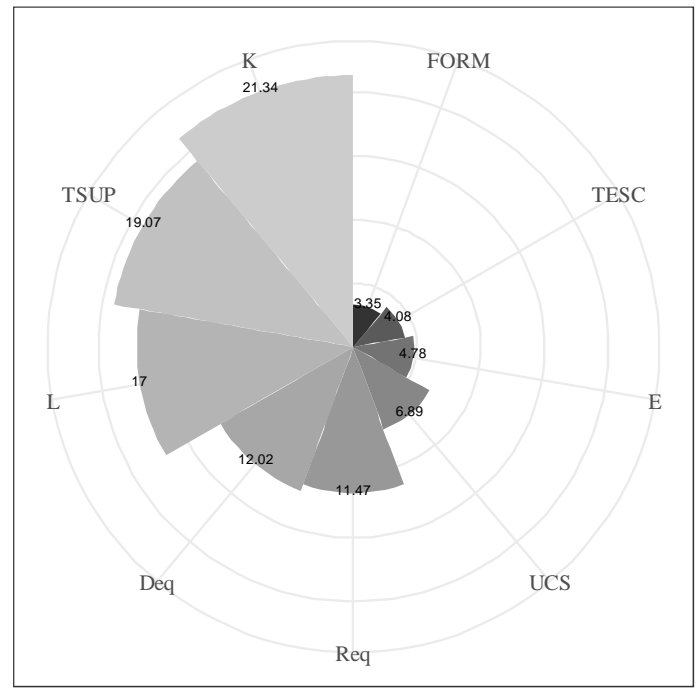

Figure 7: Relative importance of each variable according to the ANN model.

\section{REFERENCES}

[1] Sousa, R.L. (2010). Risk analysis for tunneling projects [dissertation]. Cambridge: Massachusetts Institute of Technology.

[2] Feng, X.T., Jiang, Q., Sousa, L.R., Miranda, T. (2012). Underground hydroelectric power schemes. In: Sousa LR, Vargas E Jr, Fernandes MM, Azevedo R, editors: Innovative numerical modelling in geomechanics. London: CRC Press, pp. 13-50.

[3] Sousa, L.R. (2006). Learning with accidents and damage associated to underground works. In: Matos AC, Sousa LR, Kleberger J, Pinto PL, editors: Geotechnical risk in rock tunnels. London: CRC Press; 2006. p. 7-39. 
[4] He, M., Xia, H., Jia, X,. Gong, W., Zhao, F., Liang, K. (2012). Studies on classification, criteria and control of rockbursts. J. Rock Mech Geotech Eng., 4(2), pp. 97-114.

[5] He, M., Sousa, L.R., Miranda, T., Zhu, G. (2015). Rockburst laboratory tests database Application of data mining techniques. Eng. Geol., 185, pp. 116-30.

[6] Wang, J., Zeng, X., Zhou, J. (2012). Practices on rockburst prevention and control in headrace tunnels of Jinping II hydropower station. J Rock Mech Geotech Eng. 4(3), pp. 25868.

[7] Feng, X., et al. (2012). Studies on the evolution process of rockbursts in deep tunnels. J Rock Mech Geotech Eng, 4(4), pp. 289-95.

[8] Liu, L., Wang, X., Zhang, Y., Jia, Z., Duan, Q. (2011). Tempo-spatial characteristics and influential factors of rockburst: A case study of transportation and drainage tunnels in Jinping II hydropower station. J Rock Mech Geotech Eng, 3(2), pp. 179-85.

[9] He, M.C., Jia, X.N., Gong, W.L., Liu, G.J., Zhao,, F. (2012). A modified true triaxial test system that allows a specimen to be unloaded on one surface. In: Kwasniewski M, Li X, Takahashi M, editors: True triaxial testing of rocks. London: CRC Press, pp. 251-66.

[10] Miranda, T., Sousa, L.R. (2012). Application of data mining techniques for the development of new geomechanical characterization models for rock masses. In: Sousa LR, Vargas E Jr, Fernandes MM, Azevedo R, editors: Innovative numerical modelling in geomechanics. London: CRC Press, pp. 245-64.

[11] Barai, S.K. (2003). Data Mining applications in transportation engineering. Transport, 18(5), pp. 216-23.

[12] Saitta, S., Kripakaran, P., Raphael, B., Smith, I.F. (2008). Improving system identification using clustering. J Comput Civ Eng, 22(5), pp. 292-302.

[13] Adoko, A.C., Gokceoglu, C., Wu, L., Zuo, Q.J. (2013). Knowledge-based and data-driven fuzzy modeling for rockburst prediction. Int J Rock Mech Min, 61, pp. 86-95.

[14] Chapman, P., Clinton, J., Kerber, R., Khabaza, T., Reinartz, T., Shearer, C., et al. (2000). CRISP-DM 1.0: Step-by-step data mining guide. Chicago: SPSS Inc.

[15] McPherson, B., Elsworth, D., Fairhurst, C., Kelsler, S., Onstott, T., Roggenthen, W., et al. (2003). EarthLab: A subterranean laboratory and observatory to study microbial life, fluid flow, and rock deformation. A Report to the National Science Foundation. Bethesda: Geosciences Professional Services Inc.

[16] Sousa, L.R., Miranda, T., Roggenthen, W., Sousa, R.L. (2012). Models for geomechanical character-ization of the rock mass formations at DUSEL using data mining techniques. In: Proceedings of the 46th US Rock Mechanics/Geomechanics Symposium, Jun 24-27, Chicago, IL, USA. Alexandria: American Rock Mechanics Association, pp. 1-14.

[17] R-Project.org [Internet]. Vienna: The R Foundation. 2020 [updated 2020 Apr. 15, cited 2020 May 4]. Available from: http://www.r-project.org.

[18] Cortez, P. (2010). RMiner: Data mining with neural networks and support vector machines using R. In: Rajesh R, editor: Introduction to advanced scientific softwares and toolboxes. Hong Kong: International Association of Engineers.

[19] Cortez, P., Embrechts, M.J. (2013). Using sensitivity analysis and visualization techniques to open black box data mining models. Inform Sciences, 225, pp.1-17. 